\title{
Study of Higher Education Reform under the background of Big Data
}

\author{
Wang Xidong ${ }^{1 *}$ Lu Xiaoye ${ }^{2}$ \\ 1,2 Yunnan University of Finance and Economics, \\ Yunnan, P.R.China 650221 \\ (wangxidong1987@126.com)
}

\begin{abstract}
Along with the enhancement of the education informationization, more and more educational data has been collected, analyzed and applied. Big Data will promote a revolutionary change on teachers, students, university management and even the entire education system, leading to the deconstruction and reconstruction of education principles and education forms. Consequently how to utilize learning analysis and educational data mining technology, transform the online learning data into information in action, explore the underlying value of data, to improve the teaching and learning, will undoubtedly have a positive theoretical and practical significance. The paper first interprets characteristics and technology of education data, then analyzes the multiple challenges higher education being faced with in the era of Big Data; finally in terms of teaching, learning and management these three aspects excavates the direction of higher education reform under the background of Big Data: transforming it from traditional modes to intelligentization.
\end{abstract}

Keywords-Big Data; higher education reform; educational data mining; intelligentization

\section{INTRODUCTION}

Developments of education in China have been facing many problems. However, the rapid developments on the technology of cloud computing, Big Data, learning and analysis, networking, mobile communication etc. provide important opportunities and huge possibilities in order to solve problems of education and promote the comprehensive reform and development in the field of education. Among them, the Big Data technology is undoubtedly scientific power which promotes innovations and developments of education. In recent years, Big Data constantly has a profound impact on all areas of society and gradually brings about changes of human working, living and thinking. Similarly, the "power" has a strong impact on the whole education system which is becoming subversive force of the innovation and reform of the education system.

Educational data is a subset of Big Data, referring in particular to the data in the field of education, and it is a data set which is generated in the process of the educational activities and captured according to the educational needs, all for educational development and creating huge potential value. The "bigness" of educational data not only means the sheer quantity of data but more emphasizes the huge "value" of it that it can find out the relationship, diagnose existing problems and predict development tendency from complex educational data and it plays important roles in upgrading the quality of education, promoting education fair, realizing personalized learning, optimizing the allocation of educational resources, helping education with scientific decision-making. Big Data have been incorporated into the development strategy of our country. In August 31, 2015, the State Council issued a file: notice to promote the outline of Big Data Development Action. It pointed out:" Big Data has become a new driving force to promote economic restructuring and development, a new opportunity of reshaping the competitive advantage of nation, a new way to enhance the governance capacity. Leading technology flow, material flow, capital flow and personnel flow through data flow will profoundly influence organization mode of the social division and promote the intensive production organization and innovation. To explore supporting roles Big Data plays in transformation of education, educational equity and quality ". Big Data is a hallmark of human progress in seeking quantization and understanding the world. There is no doubt that the outline will provide new thinking for the reform of higher education in china.

Under this background, in the process of the development of higher education informationization, how to introduce new technology and new method of Big Data, transform the data of massive learners' study process and path of growth kept by the online space learning, find relevant and causal relationships, in order to face the reform of higher education which is brought out by information technologies and intelligence technologies, has significance undoubtedly for both theory and practice.

\section{The Characteristics AND TeChNiQues OF Big DATA IN EDUCATION}

\section{A. The differences between Big Data and traditional data in education}

Compared with traditional education data, collecting bid data is more real-time, comprehensive and authentic which can process complex and diverse problems. The collection of traditional data is based on the users' knowledge so that the means of analysis usually comprise of statistical summary and comparative analysis. While in the era of Big Data, new 
techniques like data mining, cloud computing, internet of things and distributed storage will gradually integrated into the whole process of education which can gather more micro procedural data about teaching and learning without affecting teaching activities between teachers and students, such as the trajectory of learning of students, their time used on homework and the times of questioning and smiling made by teachers in class. The structure of Big Data in education is more complex. Normal structured data (such as scores, students' status, employment rates, attendance records etc.) is still important, however, non-structured data (such as images, videos, instructional software, learning games etc.) will play leading role.

Traditional data in education mainly takes management, structured and conclusive data as lord. These data is easy to measure and dominant. While under the background of Big Data, the key point will transform to non-structured and procedural data. These data are difficult to measure and recessive. These data, no matter on their quantity, growing rate or potential value, will all far surpass traditional education data.

\section{B. The key technique involved in analysis by Big Data in education}

\section{1) Storage mechanism of massive data}

In order to realize the sharing of high-quality educational resources, it is necessary to build an information system to support the storage to mass educational resources. At the same time, many educational institutions have begun to explore new ways of interactive learning. Educational carriers including intelligence guidance system, micro blog and forum interaction and educational games have produced more and more nonstructured data.

The Hadoop Distributed File System (HDFS), based on the technology of Big Data, supports the unified storage and management of non-structured data resources. It contains high fault tolerance and can be deployed in cheap equipment resource pool. At the same time, it provides high throughput of data access which provides the storage of Big Data in education with effective solutions.

\section{2) Establishment of analytical data model}

To support the Big Data analysis, it is necessary to establish a unified data model based on the themes about student's attendance, exam, daily performance etc., stored in information system for storage and analysis. In addition, it needs to strengthen gathering and inputting data about education process according to the need of teaching feedback, in order to establish models in views of conceptual ability, general ability, skill ability, habit ability etc. So that it can support to analyze the education processes and results.

\section{3) Application of data mining}

Data mining is a bridge between educational Big Data and intelligence education. After a long time exploration, many educators and researchers, through researches, have developed 5 techniques of extracting value from Big Data, including forecast, clustering, correlation mining, assistant judgment and discovery. Implementing these techniques can use Big Data to build a learning analyzing system for improving student's achievement and help educators guide students more effectively, making them stride forward the direction which is more suitable for them to study.

\section{The Multiple Challenges Higher EdUCATION FACE IN THE ERA OF Big DATA}

Educational data as a new concept, in the process of its development, faces challenges from the traditional impact, data sources, skills training etc.

\section{A. The impact in traditional higher education}

In the era of Big Data, the globalization and international competition of higher education greatly speed up. The borderline between formal learning and informal has blurred. The classroom is no longer the necessary space for learning, and the post-secondary teachers have lost their status as knowledge agent. The impact on higher education and postsecondary teachers, which formed from these factors, is difficult to establish.

The innovation in the field of higher education in our country is far inferior to other traditional industries. Influenced by the popularization of higher education, because of limited educational resources, regular institutions of higher learning still follows mass production mode of industrialization, thought that "one size fits all", which leads to the serious fact that trained talent persons homogenize, lacking of creativity and critical thinking.

The integration of information technology and higher education still rests on lower level, so that some of structural contradictions and problems gradually emerge. The most prominent problem is that the informatization teaching can't reflect that it is learning-centered under the high unified framework. The educational service can't satisfy the adaptable needs of increasingly diverse student population in the knowledge society. The technology can't support individual autonomous learning. The informatization mode of teaching and learning is obsolete. The assessment mechanism of learning result simplifies seriously. Evaluation contents and methods are monotonous, lacking of individuality, diversity and flexibility.

\section{B. The lack of a unified data standard}

A Unified data standard provides possibilities of getting data from different platforms or channels and then analyzing uniformly. If there is a huge difference in storage data recording standards of the structure, it will be difficult to support modeling and analysis of Big Data.

The informationization level of education workers should be improved

Most post-secondary teachers haven't been aware of the revolutionary influence Big Data brings about on higher education, and they have weak sense of crisis and lack Big Data thinking. The post-secondary teachers and administrators who have relatively weak statistical base may not process the ability of data mining and even resent new technological changes. 
To improve the educational informatization level and realize intelligence education needs to build high-quality education staff. The challenges it is mainly facing include: lack of educators, uneven distribution; also needs to put a lot of resources, continuously through training to improve staffs' informatization-cultivation.

\section{Study ON THE REFORM DiRection OF Higher EDUCATION UNDER THE BACKGROUND OF BIG DATA}

With the maturity of Big Data analysis technology, the increasing choices of using analysis tools, the reduction of technical threshold and cost, it has become possible for datadriven teaching.

\section{A. Overall understand students, accordingly teach them}

The rapid development of Big Data triggers deeper teaching informatization, shakes teachers' original ways of working and thinking, and it puts forward a lot of challenges and higher requirements of knowledge and skills for post-secondary teachers. Therefore, leading teachers to understand functions of Big Data in the reform of teaching and learning comprehensively and rationally and improving post-secondary teachers ' data literacy is of great importance.

In the learning process informationization, a large number of students' relevant learning behavior will be automatically recorded and gathered as "big learning data". Based on the application of education data, teachers can analyze students' learning path and test results, keep abreast of each student's learning situation, create a customized learning environment and personalized curriculum for each student, provide tailormade courses recommendation, and feed back to teaching timely by referencing students' basic information such as their learning behavior and so on.

\section{B. Help students with individualized learning}

The student with the aid of "Big Data" can better understand their learning status, carry out autonomous learning and improve learning efficiency. The Big Data in the field of education is inseparable from the current online education developed in full swing. The current mode of education is no longer confined to teaching, listening, midterm and final exam etc. Big Data help us to determine the feasibility and advantages and disadvantages of things with a fresh viewpoint, thoroughly present unobservable deep learning state with the traditional teaching methods, and then provide personalized teaching service for each student.

\section{Assist colleges with management and decision-making}

The college management department can gather and count the data of traditional and online educational institutions, analyze the current social hot subjects and the distribution of students, and provide a reliable basis for related system establishment, discipline establishment, education resources allocation and other decision-making behaviors. Meanwhile, the college management department can take advantage of all kinds of historical data, existing data as well as data to be generated, analyze and predict educational situation, teaching quality, educational needs, development trend for the future etc. and continue to optimize the management decision system. In daily life, through analyzing the data of librarian books borrowing, the management department can also provide an instruction for books purchase, books classification, books optimization placement etc. in later period. Through analyzing information of campus smart card consumed in canteens, supermarkets etc. can help colleges update dishes and commodities, daily amounts of meals, amounts of goods purchase etc. reasonably.

\section{CONCLUSION}

With higher education having changed from the era of IT (Information Technology) into the era of DT (Data Technology), China's higher education will usher in a new round of changes and adjustments in combination with opportunities and challenges. Post-secondary teachers should seize this historic opportunity, with Big Data view of reviewing the ecological environment of higher education in new period to embrace Big Data; with data to understand and enhance students' learning experience, enhance teachers and managers' experience. Let data increase it value in the analysis and application, promote deep integration and development of Big Data and higher education and continuously bring forth innovative ways of teaching and learning. Scientific and effective application of Big Data is the need of the development of the times in educational informationization, creativity education, education efficiency and education fair for high education, is the inevitable way to achieve intelligence education is the necessary path for the reform and development of higher education.

\section{REFERENCES}

[1] Lane, J. E. Building a Smarter University: Big Data, Innovation and Analytics [M]. New York: State University of New York Press, 2014.

[2] Gandomi, A. Haider, M. Beyond the Hype: Big Data Concepts, Methods and Analytics [J]. International Journal of Information Management, 2015, (35): 137-144

[3] U. S. Department of Education. National Education Technology Plan 2010[EB/OL]. https://www.ed.gov/sites/default/files/netp2010.pdf,201508-08.

[4] Hussey, T. Smith, P. The Trouble with Higher Education: A Critical Examination of Our Universities [M]. New York: Routledge, 2010.

[5] Provost, F. Fawcett, T. Data Science for Business: What You Need to Know About Data Mining and Data-Analytic Thinking [M]. California: O'Reilly, 2013.

[6] Greller, W. Drachsler, H. Translating Learning into Numbers: A Genetic Framework for Learning Analytics [J]. Educational Technology\& Society, 2012, 15 (3): 42-57.

[7] Romero, C. Ventura, S. Pechenizky, M. Baker, R. Handbook of Educational Data Mining [M]. Florida: CRC Press Inc. , 2010. 